\title{
SISTEM PAKAR UNTUK MENDETEKSI KESALAHAN ELEKTRODA PADA PROSES WELDING FRAME THERMOSTAT PADA SOULPLATE MENGGUNAKAN METODEFORWARD CHAINING BERBASIS WEB (STUDI KASUS PT PHILIPS)
}

\author{
Sestri novia rizki ${ }^{1}$, Feriki Lilik Djoenardi ${ }^{2}$ \\ ${ }^{12}$ Fakultas Teknik Universitas Putera Batam \\ email : novia.sestri@gmail.com \\ Submitted: 16-03-2017, Reviewed: 17 -03- 2017, Accepted 18-03-2017 \\ http://dx.doi.org/10.22202/jei.2017.v3i2.2248
}

\begin{abstract}
The use of SMAW (Shielded Metal Arc Welding) in the industrial world is enough widely used. With this machine the human greatly helped by the need to make a metal object. So that by the frequent use of these tools, the more susceptible it is also a tool damage. Technicians machines supplied by the company are not proportional to the number of machines. Therefore, to help resolve this issue needs an expert system that can act as an assistant to the engineer. Data relating to the damage processed using forward chaining expert system. Expert systems are made using the programming language PHP and MySQL database so as to produce an expert system to detect damage SMAW web based. So it can help technicians solve problems SMAW and can also be used for the source of knowledge about the condition and its causes and solutions to overcome them.
\end{abstract}

Keywords: expert systems, damage detection, Shielded Metal Arc Welding, forward chaining

\section{PENDAHULUAN}

Di tempat industries yang maju seperti batam banyak perusahaan yang memanfaatkan teknik pengelasan (welding) dengan mengunakan Las Elektroda terbungkus welding/ SMAW (Shielded Metal Arc Welding). Salah satu perusahaan yang menggunakan SMAW untuk mendukung kegiatan produksi adalah PT Philips Industries Batam. Ini dikarenakan benda yang ingin dihubungnan dengan logam lainnya tidak terlalu besar, dan perosesnya cukup cepat dan tidak membahayakan.

Permasalahan yang terjadi pada mesin welding biasanya disebabkan oleh kerusakan pada komponen-komponen tertentu. Penyebab kerusakan tersebut dapat diidentifikasi melalui kondisi kerusakannya. Kesalahan elektroda yang menghasilkan output sebagai kondisinya antara lain proses welding goyang, proses welding mudah lepas, proses welding lepas, dan sebagainya. Sebelum terjadi kerusakan lain yang lebih parah lagi, penyebab kerusakan harus segera ditemukan dan ditangani sehingga mesin welding dapat beroprasi kembali dengan normal. karena keterbatasan kemampuan atau pengetahuan teknisi maka dibutuhkan system pakar yang dapat berperan sebagai assistant bagi teknisi dalam menganalisa permasalahan tentang mesin SMAW.

Sistem pakar adalah sistem yang mengunakan pengetahuan manusia yang dimasukan ke dalam komputer untuk memecahakan masalah-masalah yang biasanya 


\section{Jurnal Edik Informatika}

ISSN : 2407-0491

E-ISSN : 2541-3716

Penelitian Bidang Komputer Sains dan Pendidikan Informatika V3.i2(211-225)

diselesaikan oleh pakar. Sistem pakar yang baik dirancang dan dibangun agar dapat menyelesaikan suatu permasalahan tertentu dengan meniru kerja dari seorang pakar. Dengan sistem pakar ini, orang awam pun dapat menyelesaikan masalah yang cukup rumit yang sebenarnya hanya dapat diselesaikan dengan bantuan para pakar. Bagi para pakar, sistem pakar ini juga akan membantu aktivitasnya sebagai asisten yang cukup cerdas.

Dalam membuat suatu kesimpulan, system pakar melakukan sebuah proses yang dinamakan perunutan atau penelusuran. Menurut (Hartati dan Iswanti; 2008: 45) perunutan yang dimulai dengan menampilkan kumpulan data atau fakta yang meyakinkan menuju konklusi akhir. Forward chaining biasa juga disebut sebagai penalaran forward (forward reasoning) atau pencarian yang dimotori data (data driven search). Jadi di mulai dari premis-premis atau informasi masukan (If) dahulu kemudian menuju konklusi atau derived information (then) atau dapat dimodelkan sebagai berikut:

IF(informasi masukan)

THEN (konklusi)

Informasi masukan dapat berupa data, bukti, temuan, atau pengamatan. Sedangkan kolusi dapat berupa tujuan, hipotesa, penjelasan, atau diagnosa. Sehingga jalannya penalaran runtut maju dapat dimulai dari data menuju tujuan, dari data menuju tujuan, dari bukti menuju hipotesa, dari temuan menuju penjelasan, atau dari pengamatan menuju diagnosa (Hartati dan Iswanti; 2008: 45).

Berdasarkan pembatasan masalah tersebut, maka penulis memutuskan untuk merumuskan masalah sebagai berikut: (1) Bagaimana menerapkan model representasi pengetahuan berbasis kaidah produksi (production rule) agar dapat digunakan sebagai kaidah atau aturan dalam sistem pakar untuk mendeteksi kesalahan mesin (SWAN) berbasis web?, (2) Bagaimana menerapkan metode Forward Chaining dalam sistem pakar untuk mendeteksi kesalahan mesin (SMAW) berbasis web?, dan (3) Bagaimana perancangan sistem pakar untuk mendeteksi kerusakan elektrode pada mesin (SMAW) mengunakan metode Forward Chaining berbasis web?

Berdasarkan pembatasan masalah tersebut, maka penulis memutuskan untuk merumuskan masalah sebagai berikut: (1) Bagaimana menerapkan model representasi pengetahuan berbasis kaidah produksi (production rule) agar dapat digunakan sebagai kaidah atau aturan dalam sistem pakar untuk mendeteksi kesalahan mesin (SWAN) berbasis web?, (2) Bagaimana menerapkan metode Forward Chaining dalam sistem pakar untuk mendeteksi kesalahan mesin (SMAW) berbasis web?, dan (3) Bagaimana perancangan sistem pakar untuk mendeteksi kerusakan elektrode pada mesin (SMAW) mengunakan metode Forward Chaining berbasis web?

Tujuan penelitian ini adalah: (1) Untuk menerapkan model representasi pengetahuan berbasis kaidah produksi (production rule) agar dapat digunakan sebagai kaidah atau aturan dalam sistem pakar untuk mendeteksi kesalahan mesin (SWAN) berbasis web, (2) Untuk menerapkan metode Forward Chaining dalam sistem pakar untuk mendeteksi kesalahan mesin $(S M A W)$ berbasis web, dan (3) Untuk perancangan sistem pakar untuk mendeteksi kerusakan elektrode pada mesin (SMAW) mengunakan metode Forward Chaining berbasis web.

Penelitian ini diharapkan mampu memberikan manfaat baik dari aspek teoritis (keilmuan) maupun aspek praktis (kegunaan). Manfaat yang akan didapatkan dari penelitian ini adalah: (1) Aspek teoritis (keilmuan) Mengembangkan ilmu pengetahuan tentang sistem pakar agar dapat diterapkan dalam bidang perangkat mesin yaitu mesin (SMAW) sebagai menambah wawasan bagi pembacanya, dan (2) Aspek praktis 


\section{Jurnal Edik Informatika}

ISSN : 2407-0491

E-ISSN : 2541-3716

Penelitian Bidang Komputer Sains dan Pendidikan Informatika V3.i2(211-225)

(kegunaan) Secara khusus, penelitian ini menghasilkan sistem pakar yang bermanfaat untuk membantu teknisi dalam menyelesaikan masalah yang berkaitan dengan kerusakan mesin (SMAW). Manfaat penelitian ini secara umum adalah untuk membantu pengguna awam (karyawan) yang bukan pakar agar dapat menyelesaikan permasalahan yang berkaitan dengan kerusanan mesin (SMAW) dan sebagai media edukasi untuk mengetahui permasalahan mesin $(S M A W)$.

\section{LANDASAN TEORI}

Kecerdasan Buatan atau Artificial Intelligence (AI)

Kecerdasan buatan adalah salah satu bidang ilmu komputer yang mendayagunakan komputer sehingga dapat berlaku seperti manusia (Hartati dan Iswanti; 2008: 1).

\section{Sistem Pakar (Expert System)}

Menurut Kusrini (2008: 3) Sistem pakar adalah aplikasi berbasis komputer yang digunakan untuk menyelesaikan masalah sebagaimana yang dipikirkan oleh pakar. Pakar yang dimaksud di sini adalah orang yang mempunyai keahlian khusus yang dapat menyelesaikan masalah yang tidak dapat diselesaikan oleh orang awam.sebagai contoh, dokter adalah seorang pakar yang mampu mendiaknosis penyakit yang diderita pasien, serta dapat memberikan penatalaksanaan terhadap penyakit tersebut. Tidak semua orang dapat mengambil keputusan mengenai diagnosis dan memberikan penatalaksnaan suatu penyakit.

Sistem pakar adalah sistem yang mengunakan pengetahuan manusia yang dimasukan ke dalam komputer untuk memecahkan masalah-masalah yang biasanya diselesaikan oleh pakar. Menurut Imam Gunawan (September 2013 vol.6 no.2) dalam Turban (2005).

Pada sistem pakar berbasis rute, domain pengetahuan direpresentasikan dalam sebuah kumpulan rute berbentuk IF-THEN, sedangkan data direpresentasikan dalam sebuah kumpulan fakta-fakta tentang kejadian saat ini. Mesin inferensi membandingkan asing-masing rute yang tersimpan dalam basis pengetahuan dengan fakta-fakta yang terdapat dalam database. Jika bagian IF (kondisi) dari rute cocok dengan fakta, maka rute dieksekusi dan bagian THEN (aksi) diletakan dalam database sebagai fakta baru yang ditambahkan (Sutojo, dkk., 2011: 171).

\section{Runut Maju (Forward Chaining)}

Forward Chaining adalah teknik pencarian yang dimulai dengan fakta yang diketahui, kemudian mencocokan fakta-fakta tersebut dengan bagian IF dari rute IF-THEN. Bila ada fakta yang cocok dengan bagian IF, maka rute tersebut dieksekusi. Bila sebuah rute dieksekusi, maka sebuah fakta baru (bagian THEN) ditambahkan ke dalam database. Setiap kali pencocokan, dimulai dari rute teratas. Setiap rute hanya boleh dieksekusi sekali saja. Proses pencocokan berhenti bila tidak ada lagi rute yang bisa dieksekusi. Metode pencarian yang digunakan adalah Depth-First Search (DFS), Breadth-First Search (BFS) atau Best First Search (Sutojo, dkk., 2011: 171).

Menurut Wilson (1998) dalam kusrini (2008: 8-11) runut maju berarti menggunakan himpunan aturan kondisi-aksi. Dalam metode ini, data digunakan untuk menentukan aturan mana yang akan dijalankan, kemudian aturan tersebut dijalankan. Memungkinkan proses menambahkan data ke memori kerja. Proses diulang sampai ditemukan suatu hasil.

\section{Runut Balik (Backward Chaining)}

Backward Chaining adalah metode inferensi yang bekerja mundur ke arah kondisi awal. Proses diawali dari Goal (yang berada di bagian THEN dari rute IF-THEN), kemudian pencarian mulai dijalankan untuk mencocokkan apakah fakta-fakta yang ada cocok dengan premis-premis di bagian IF. Jika 


\section{Jurnal Edik Informatika}

ISSN : 2407-0491

E-ISSN : 2541-3716

Penelitian Bidang Komputer Sains dan Pendidikan Informatika V3.i2(211-225)

cocok, rute dieksekusi, kemudian hipotesis di bagian THEN ditempatkan di basis data sebagai fakta baru. Jika tidak cocok, simpan premis di bagian IF ke dalam stack sebagai subGoal. Proses berakhir jika Goal ditemukan atau tidak ada rute yang bisa membuktikan kebenaran dari subGoal atau Goal (Sutojo, dkk., 2011: 178).

\section{Shield Metal Arc Welding (SMAW)}

Menurut Sukaini, et al. (2013: 1) Shield Metal Arc Welding (SMAW) merupakan suatu teknik pengelasan dengan menggunakan arus listrik yang Membentuk busur arus dan elektroda berselaput. Di dalam pengelasan $S M A W$ ini terjadi gas pelindung ketika elektroda terselaput itu mencair, sehingga dalam proses ini tidak diperlukan tekanan/pressure gas inert untuk menghilangkan pengaruh oksigen atau udara yang dapat menyebabkan korosi atau gelembung-gelembung di dalam hasil pengelasan. Proses pengelasan terjadi karena adanya hambatan arus listrik yang mengalir diantara elektroda dan bahan las yang menimbulkan panas mencapai 3000 oC, sehingga membuat elektroda dan bahan yang akan dilas mencair.

\section{Kerangka Pemikiran}

Berikut ini adalah kerangka pemikiran yang mendasari penelitian ini:

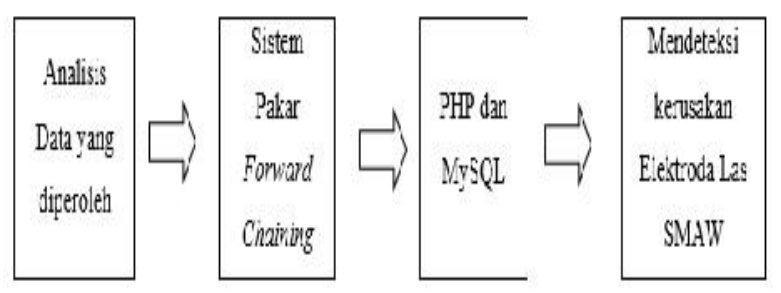

terlebih dahulu agar lebih sederhana dan mudah dilakukan proses pengolahan datanya. Data-data tersebut kemudian diolah menggunakan metode sistem pakar forward chaining untuk membuat aturan (rule) yang akan digunakan. Sistem pakar dengan metode forward chaining dibuat menggunakan bahasa pemrograman $P H P$ dan database $M y S Q L$ sehingga menghasilkan sebuah sistem pakar untuk mendeteksi kerusakan las SMAW menggunakan metode forward chaining berbasis web.

\section{METODE PENELITIAN \\ Desain Penelitian}

Menurut Sarwono (2006: 27) desain penelitian merupakan alat yang akan menentukan berhasil atau tidaknya suatu penelitian yang sedang dilakukan. Desain penelitian yang baik akan mendukung jalannya penelitian dengan baik pula. Desain penelitian berfungsi sebagai penuntun bagi peneliti yang akan menentukan arah berlangsungnya proses penelitian secara benar dan tepat sesuai dengan tujuan yang ditetapkan. Desain penelitian yang benar adalah desain yang terhindar dari sumber potensial kesalahan dalam proses penelitian secara keseluruhan seperti kesalahan dalam perencanaan, pengumpulan data, melakukan analisis data, dan kesalahan dalam pelaporan hasil penelitian. Tanpa desain penelitian yang benar, peneliti tidak mempunyai pedoman arah penelitian yang jelas sehingga penelitian tidak dapat dilakukan dengan baik (Sarwono, 2006: 79).

Penelitian ini menggunakan desain penelitian dengan beberapa tahap proses penelitian seperti yang terlihat pada gambar di bawah ini.

\section{Gambar 1 Kerangka Pemikiran}

(Sumber: Data Penelitian: 2017)

Data-data yang dibutuhkan berkaitan dengan permasalahan las $S M A W$ dianalisis 


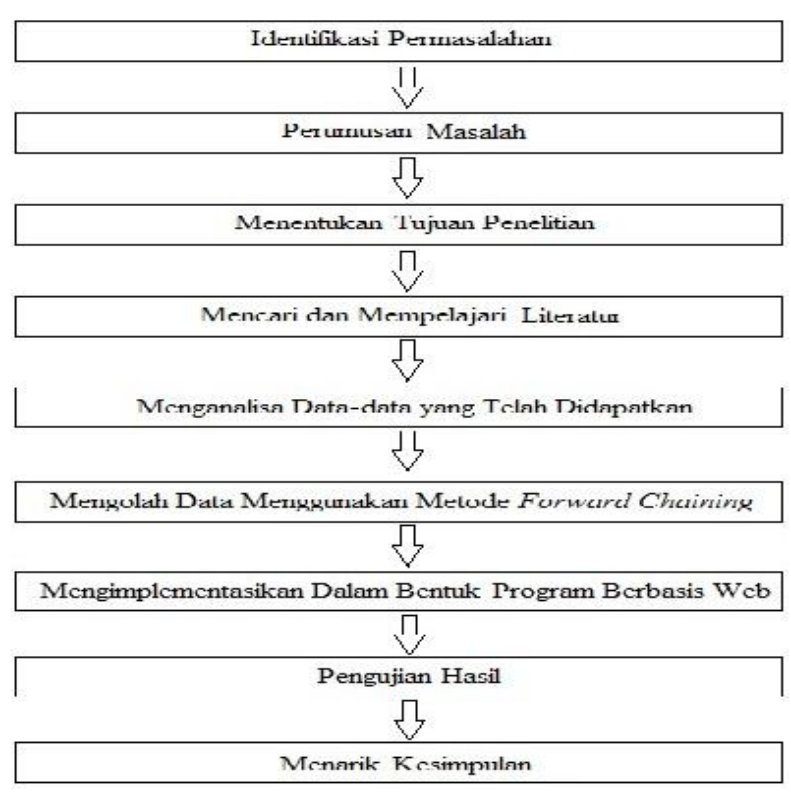

Gambar 2 Desain Penelitian

(Sumber: Data Penelitian, 2017)

\section{Teknik Pengumpulan Data}

Teknik pengumpulan data yang digunakan dalam penelitian ini adalah:

\section{Wawancara}

Untuk mendapatkan data-data yang berkaitan dengan penelitian, peneliti melakukan wawancara langsung dengan Bapak Tri Pranowo yang bekerja sebagai Senior Production Engineer di PT Philips Industries Batam. Dalam metode wawancara, alat bantu yang digunakan peneliti berupa alat tulis untuk menulis semua apa yang ditanyakan selama proses wawancara dilakukan. Pedoman wawancara yang digunakan berupa garis-garis besar permasalahan yang akan ditanyakan yaitu halhal yang berkaitan dengan SMAW dan kerusakan yang dapat terjadi pada SMAW.

\section{Studi literatur}

Peneliti melakukan studi literatur dengan mengumpulkan, membaca, dan memahami referensi teoritis yang berasal dari buku-buku teori, buku elektronik (e-book), jurnal-jurnal penelitian, dan sumber pustaka otentik lainnya yang berkaitan dengan penelitian. Studi literatur bertujuan untuk menemukan variabel yang akan diteliti, membedakan hal-hal yang sudah dilakukan dan menentukan hal yang perlu dilakukan, melakukan sintesa dan memperoleh perspektif baru, dan menentukan makna dan hubungan antar variabel (Sarwono, 2006: 47).

\section{Desain Basis Pengetahuan}

Sumber pengetahuan dan fakta diperoleh melalui wawancara dengan pakar dan studi literatur tentang materi yang berkaitan dengan $S M A W$. Sumber pengetahuan dan fakta yang didapat berupa data-data yang berhubungan dengan bagian kerusakan SMAW, kondisi kerusakan SMAW, penyebab kerusakan dan solusi mengatasinya. Pengetahuan dan fakta tersebut ditampilkan dalam tabel penyebab (Tabel 1), tabel kondisi (Tabel 2), tabel operasional variabel (Tabel 3) dan tabel aturan (Tabel 4).

\begin{tabular}{|l|l|l|}
\hline $\begin{array}{l}\text { Kode } \\
\text { Penye } \\
\text { bab }\end{array}$ & Nama Penyebab 1 Tabel Penyebab \\
\hline & & $\begin{array}{l}\text { Solusi } \\
\text { Pencegahan yang } \\
\text { dapat dilakukan } \\
\text { supaya tidak } \\
\text { terjadi porosity } \\
\text { antara lain: Jaga } \\
\text { arc length selalu } \\
\text { tepat Bersihkan } \\
\text { benda kerja dari } \\
\text { minyak, oli, cat, } \\
\text { debu, lapisan, } \\
\text { slag, embun, dan } \\
\text { kotoran sebelum } \\
\text { melakukan } \\
\text { pengelasan. } \\
\text { Gunakan } \\
\text { elektroda yang } \\
\text { kering. }\end{array}$ \\
\hline POROSITY & $\begin{array}{l}\text { Pencegahan yang } \\
\text { dapat dilakukan: } \\
\text { Bersihkan } \\
\text { terlebih dahulu } \\
\text { slag }\end{array}$ \\
\hline
\end{tabular}

\section{Diterbitkan Oleh Program Studi Pendidikan Informatika STKIP PGRI Sumbar}




\section{Jurnal Edik Informatika \\ ISSN : 2407-0491 \\ E-ISSN : 2541-3716}

Penelitian Bidang Komputer Sains dan Pendidikan Informatika V3.i2(211-225)

\begin{tabular}{|c|c|c|c|c|}
\hline & & $\begin{array}{lr}\text { menempel } & \\
\text { sebelum } & \\
\text { mengelas } & \text { pada } \\
\text { lapisan } & \text { di } \\
\text { atasnya. } & \end{array}$ & & pengelasan. \\
\hline \multirow{8}{*}{ P03 } & \multirow{8}{*}{$\begin{array}{l}\text { Cacat Las } \\
\text { Kurang } \\
\text { Menyatu (Lack } \\
\text { of Fusion) }\end{array}$} & \multirow{8}{*}{$\begin{array}{l}\text { Pencegahan yang } \\
\text { dapat dilakukan } \\
\text { yakni:Tingkatkan } \\
\text { arus listrik, bila } \\
\text { perlu ganti } \\
\text { dengan ukuran } \\
\text { elektroda yang } \\
\text { lebih besar. } \\
\text { Posisikan } \\
\text { elektroda tepat } \\
\text { pada sambungan. } \\
\text { Kontrol sudut } \\
\text { elektroda dengan } \\
\text { tepat. Bersihkan } \\
\text { benda kerja dari } \\
\text { oli, minyak, } \\
\text { embun, kotoran, } \\
\text { dan cat sebelum } \\
\text { anda mengelas. }\end{array}$} & \multicolumn{2}{|c|}{ Sumber: Data Penelitian (2017) } \\
\hline & & & $\begin{array}{l}\text { Kode } \\
\text { Kondisi }\end{array}$ & Nama Kondisi \\
\hline & & & $\mathrm{K} 1$ & $\begin{array}{l}\text { Hasil lasan disisi kanan dan kiri } \\
\text { bahan banyak terdapat bekas } \\
\text { percikan las/ bintik-bintik akibat } \\
\text { las }\end{array}$ \\
\hline & & & $\mathrm{K} 2$ & Hasil kurang bagus (kurang pas) \\
\hline & & & K3 & $\begin{array}{l}\text { Sebagian cairan las jatuh ke bagian } \\
\text { bawah }\end{array}$ \\
\hline & & & K4 & $\begin{array}{l}\text { Kondisi material yang basah } \\
\text { lembab, berkarat atau berminyak }\end{array}$ \\
\hline & & & K5 & Panjang busur terlalu besar \\
\hline & & & K6 & Hasil lasan seperti mengunung \\
\hline \multirow{9}{*}{ P04 } & \multirow{9}{*}{$\begin{array}{l}\text { Cacat Las } \\
\text { Kurang } \\
\text { Penetrasi (Lack } \\
\text { of Penetration) }\end{array}$} & \multirow{9}{*}{$\begin{array}{l}\text { Pencegahan yang } \\
\text { dapat dilakukan } \\
\text { untuk } \\
\text { menghindari } \\
\text { kurangnya } \\
\text { penetrasi antara } \\
\text { lain: Pembuatan } \\
\text { groove harus } \\
\text { tepat di mana } \\
\text { mampu } \\
\text { menyediakan } \\
\text { akses pada bagian } \\
\text { bawah } \\
\text { sambungan. } \\
\text { Tingkatkan arus } \\
\text { listrik, bila perlu } \\
\text { gunakan } \\
\text { elektroda yang } \\
\text { lebih besar. } \\
\text { Kontrol kondisi } \\
\text { busur las, kurangi } \\
\text { kecepatan }\end{array}$} & K7 & $\begin{array}{l}\text { Logam las mencair melewati teba } \\
\text { benda }\end{array}$ \\
\hline & & & K8 & $\begin{array}{l}\text { Logam las tidak menutupi bagian } \\
\text { bawah sambungan }\end{array}$ \\
\hline & & & K9 & $\begin{array}{l}\text { Tidak menempel / menjadi satu } \\
\text { saat proses lasan }\end{array}$ \\
\hline & & & K10 & $\begin{array}{l}\text { Hasil lasan kurang kuat / mudal } \\
\text { lepas }\end{array}$ \\
\hline & & & K11 & Terdapat rongga dihasil lasan \\
\hline & & & K12 & Terdapat kotoran dimaterial \\
\hline & & & K13 & $\begin{array}{l}\text { Terdapat rongga besar berbentuk } \\
\text { bola yang tunggal atau tidak } \\
\text { mengelompok }\end{array}$ \\
\hline & & & K14 & Mengelas terlalu cepat \\
\hline & & & \multicolumn{2}{|c|}{ Sumber: Data Penelitian (2017) } \\
\hline
\end{tabular}




\section{Jurnal Edik Informatika \\ ISSN : 2407-0491 \\ E-ISSN : 2541-3716}

Penelitian Bidang Komputer Sains dan Pendidikan Informatika V3.i2(211-225)

Tabel 3 Operasional Variabel

\begin{tabular}{|c|c|c|c|c|c|c|c|}
\hline \multirow{2}{*}{ Variabel } & \multirow{2}{*}{ Indikator } & \multirow{2}{*}{$\begin{array}{c}\text { Pertanyaa } \\
n\end{array}$} & \multirow{2}{*}{$\begin{array}{l}\text { Kode } \\
\text { kondis } \\
\text { i }\end{array}$} & & & $\mathrm{ng}$ ? & \\
\hline & & & & & \multirow[b]{2}{*}{$\begin{array}{l}\text { Logam las } \\
\text { mencair } \\
\text { melewati tebal } \\
\text { benda }\end{array}$} & \multirow{2}{*}{$\begin{array}{l}\text { Apakah } \\
\text { logam las } \\
\text { mencair } \\
\text { melewati } \\
\text { tebal } \\
\text { benda? }\end{array}$} & \multirow[b]{2}{*}{ K7 } \\
\hline \multirow{10}{*}{$\begin{array}{c}\text { POROSI } \\
T Y \\
(\mathrm{P} 01)\end{array}$} & \multirow{3}{*}{$\begin{array}{l}\text { Hasil lasan } \\
\text { disisi kanan } \\
\text { dan kiri bahan } \\
\text { banyak } \\
\text { terdapat bekas } \\
\text { percikan las/ } \\
\text { bintik-bintik } \\
\text { akibat las }\end{array}$} & \multirow{3}{*}{$\begin{array}{l}\text { Apakah } \\
\text { hasil } \\
\text { lasan } \\
\text { disisi } \\
\text { kanan dan } \\
\text { kiri bahan } \\
\text { banyak } \\
\text { terdapat } \\
\text { bekas } \\
\text { percikan } \\
\text { las/ } \\
\text { bintik- } \\
\text { bintik } \\
\text { akibat las } \\
?\end{array}$} & \multirow{3}{*}{$\mathrm{K} 1$} & & & & \\
\hline & & & & & $\begin{array}{l}\text { Mengelas } \\
\text { terlalu cepat }\end{array}$ & $\begin{array}{l}\text { Apakah } \\
\text { mengelas } \\
\text { terlalu } \\
\text { cepat? }\end{array}$ & K14 \\
\hline & & & & \multirow{6}{*}{$\begin{array}{c}\text { Slag } \\
\text { Inclusion } \\
\text { (P02) }\end{array}$} & $\begin{array}{l}\text { Logam las } \\
\text { mencair } \\
\text { melewati tebal } \\
\text { benda }\end{array}$ & $\begin{array}{l}\text { Apakah } \\
\text { logam las } \\
\text { mencair } \\
\text { melewati } \\
\text { tebal } \\
\text { benda? }\end{array}$ & K7 \\
\hline & $\begin{array}{l}\text { Hasil kurang } \\
\text { bagus } \\
\text { pas) }\end{array}$ & $\begin{array}{l}\text { ? } \\
\text { Apakah } \\
\text { hasil } \\
\text { kurang } \\
\text { bagus } \\
\text { (kurang } \\
\text { pas)? }\end{array}$ & $\mathrm{K} 2$ & & $\begin{array}{l}\text { Logam las } \\
\text { tidak menutupi } \\
\text { bagian bawah } \\
\text { sambungan }\end{array}$ & $\begin{array}{l}\text { Apakah } \\
\text { logam las } \\
\text { tidak } \\
\text { menutupi } \\
\text { bagian } \\
\text { bawah }\end{array}$ & K8 \\
\hline & \multirow[b]{2}{*}{$\begin{array}{l}\text { Sebagian } \\
\text { cairan las jatuh } \\
\text { ker bagian } \\
\text { bawah }\end{array}$} & \multirow{2}{*}{$\begin{array}{l}\text { Apakah } \\
\text { sebagian } \\
\text { cairan las } \\
\text { jatuh ke } \\
\text { bagian } \\
\text { bawah? }\end{array}$} & \multirow[b]{2}{*}{ K3 } & & & $\begin{array}{l}\text { sambunga } \\
\text { n? }\end{array}$ & \\
\hline & & & & & \multirow{2}{*}{$\begin{array}{l}\text { Tidak } \\
\text { menempel / } \\
\text { menjadi satu } \\
\text { saat proses } \\
\text { lasan }\end{array}$} & \multirow{2}{*}{$\begin{array}{l}\text { Apakah } \\
\text { tidak } \\
\text { menempel } \\
\text { / menjadi } \\
\text { satu saat } \\
\text { proses } \\
\text { lasan? }\end{array}$} & \multirow[t]{2}{*}{ K9 } \\
\hline & \multirow[b]{2}{*}{$\begin{array}{l}\text { Kondisi } \\
\text { material yang } \\
\text { basah, lembab, } \\
\text { berkarat atau } \\
\text { berminyak }\end{array}$} & \multirow{2}{*}{$\begin{array}{l}\text { Apakah } \\
\text { kondisi } \\
\text { material } \\
\text { yang } \\
\text { basah, } \\
\text { lembab, } \\
\text { berkarat } \\
\text { atau } \\
\text { berminya } \\
\text { k? }\end{array}$} & \multirow[b]{2}{*}{$\mathrm{K} 4$} & & & & \\
\hline & & & & & $\begin{array}{l}\text { Hasil lasan } \\
\text { kurang kuat / } \\
\text { mudah lepas }\end{array}$ & $\begin{array}{l}\text { Apakah } \\
\text { hasil } \\
\text { lasan } \\
\text { kurang } \\
\text { kuat / } \\
\text { mudah } \\
\text { lepas? } \\
\end{array}$ & K10 \\
\hline & $\begin{array}{l}\text { Panjang busur } \\
\text { terlalu besar }\end{array}$ & $\begin{array}{l}\text { Apakah } \\
\text { panjang } \\
\text { busur } \\
\text { terlalu } \\
\text { besar? }\end{array}$ & K5 & \multirow{2}{*}{$\begin{array}{c}\text { Cacat Las } \\
\text { Kurang } \\
\text { Menyatu } \\
\text { (Lack of } \\
\text { Fusion) } \\
\text { (P03) }\end{array}$} & $\begin{array}{l}\text { Logam las } \\
\text { mencair } \\
\text { melewati tebal } \\
\text { benda }\end{array}$ & $\begin{array}{l}\text { Apakah } \\
\text { logam las } \\
\text { mencair } \\
\text { melewati } \\
\text { tebal }\end{array}$ & $\mathrm{K} 7$ \\
\hline & $\begin{array}{l}\text { Hasil lasan } \\
\text { seperti } \\
\text { mengunung }\end{array}$ & $\begin{array}{l}\text { Apakah } \\
\text { hasil } \\
\text { lasan } \\
\text { seperti }\end{array}$ & K6 & & $\begin{array}{l}\text { Logam las } \\
\text { tidak menutupi } \\
\text { bagian bawah }\end{array}$ & $\begin{array}{l}\text { benda? } \\
\text { Apakah } \\
\text { logam las } \\
\text { tidak }\end{array}$ & K8 \\
\hline
\end{tabular}


ISSN : 2407-0491

Jurnal Edik Informatika

E-ISSN : 2541-3716

Penelitian Bidang Komputer Sains dan Pendidikan Informatika V3.i2(211-225)

\begin{tabular}{|c|c|c|c|}
\hline & sambungan & $\begin{array}{l}\text { menutupi } \\
\text { bagian } \\
\text { bawah } \\
\text { sambunga } \\
\text { n? }\end{array}$ & \\
\hline & $\begin{array}{l}\text { Tidak } \\
\text { menempel / } \\
\text { menjadi satu } \\
\text { saat proses } \\
\text { lasan }\end{array}$ & $\begin{array}{l}\text { Apakah } \\
\text { tidak } \\
\text { menempel } \\
\text { / menjadi } \\
\text { satu saat } \\
\text { proses } \\
\text { lasan? }\end{array}$ & K9 \\
\hline & $\begin{array}{l}\text { Hasil lasan } \\
\text { kurang kuat / } \\
\text { mudah lepas }\end{array}$ & $\begin{array}{l}\text { Apakah } \\
\text { hasil } \\
\text { lasan } \\
\text { kurang } \\
\text { kuat / } \\
\text { mudah } \\
\text { lepas? }\end{array}$ & K10 \\
\hline & $\begin{array}{l}\text { Terdapat } \\
\text { kotoran } \\
\text { dimaterial }\end{array}$ & $\begin{array}{l}\text { Apakah } \\
\text { terdapat } \\
\text { kotoran } \\
\text { dimaterial } \\
?\end{array}$ & $\mathrm{~K} 12$ \\
\hline & $\begin{array}{l}\text { Mengelas } \\
\text { terlalu cepat }\end{array}$ & $\begin{array}{l}\text { Apakah } \\
\text { mengelas } \\
\text { terlalu } \\
\text { cepat? }\end{array}$ & K14 \\
\hline \multirow{3}{*}{$\begin{array}{c}\text { Cacat Las } \\
\text { Kurang } \\
\text { Penetrasi } \\
\text { (Lack of } \\
\text { Penetrati } \\
\text { on) (P04) }\end{array}$} & $\begin{array}{l}\text { Logam las } \\
\text { mencair } \\
\text { melewati tebal } \\
\text { benda }\end{array}$ & $\begin{array}{l}\text { Apakah } \\
\text { logam las } \\
\text { mencair } \\
\text { melewati } \\
\text { tebal } \\
\text { benda? }\end{array}$ & K7 \\
\hline & $\begin{array}{l}\text { Logam las } \\
\text { tidak menutupi } \\
\text { bagian bawah } \\
\text { sambungan }\end{array}$ & $\begin{array}{l}\text { Apakah } \\
\text { logam las } \\
\text { tidak } \\
\text { menutupi } \\
\text { bagian } \\
\text { bawah } \\
\text { sambunga } \\
\text { n? }\end{array}$ & K8 \\
\hline & $\begin{array}{l}\text { Tidak } \\
\text { menempel / } \\
\text { menjadi satu } \\
\text { saat proses } \\
\text { lasan }\end{array}$ & $\begin{array}{l}\text { Apakah } \\
\text { tidak } \\
\text { menempel } \\
\text { / menjadi } \\
\text { satu saat } \\
\text { proses } \\
\text { lasan? }\end{array}$ & K9 \\
\hline
\end{tabular}

\begin{tabular}{|l|l|l|l|}
\hline & $\begin{array}{l}\text { Terdapat } \\
\text { kotoran } \\
\text { dimaterial }\end{array}$ & $\begin{array}{l}\text { Apakah } \\
\text { terdapat } \\
\text { kotoran } \\
\text { dimaterial }\end{array}$ & K12 \\
\hline
\end{tabular}

Sumber: Data Penelitian (2017)

Tabel 4 Tabel Aturan

\begin{tabular}{|l|l|}
\hline Kode Penyebab & Kode Kondisi \\
\hline P01 & $\begin{array}{l}\text { K1,K2, K3, K4, K5, K6, } \\
\text { K7, K14 }\end{array}$ \\
\hline P02 & K7, K8, K9, K10 \\
\hline P03 & $\begin{array}{l}\text { K7, K8, K9, K10, K12, } \\
\text { K14 }\end{array}$ \\
\hline P04 & K7, K8, K9, K12 \\
\hline
\end{tabular}

Sumber: Data Penelitian (2017)

Berdasarkan data aturan yang telah disusun, maka kaidah (rule) yang akan digunakan dalam sistem pakar adalah sebagai berikut:

1. Kaidah 1: IF $\mathrm{K} 1$ AND $\mathrm{K} 2$ AND $\mathrm{K} 3$ $A N D \mathrm{~K} 4 A N D \mathrm{~K} 5$ AND K6 AND K7 AND K14 THEN P01

2. Kaidah 2: IF K7 AND K8 AND K9 AND K10 THEN K02

3. Kaidah 3: IF K7 AND K8 AND K9 AND K10 AND K12 AND K14 THEN $\mathrm{P} 03$

4. Kaidah 2: IF K7 AND K8 AND K9 AND K12 THEN K04

\section{Struktur Kontrol (Mesin Inferensi)}

Mesin inferensi dalam sistem pakar ini menggunakan metode penelusuran forward chaining. Berikut ini adalah gambar flowchart mesin inferensi yang digunakan dalam sistem pakar ini. 


\section{Jurnal Edik Informatika \\ ISSN : 2407-0491 \\ E-ISSN : 2541-3716}

Penelitian Bidang Komputer Sains dan Pendidikan Informatika V3.i2(211-225)

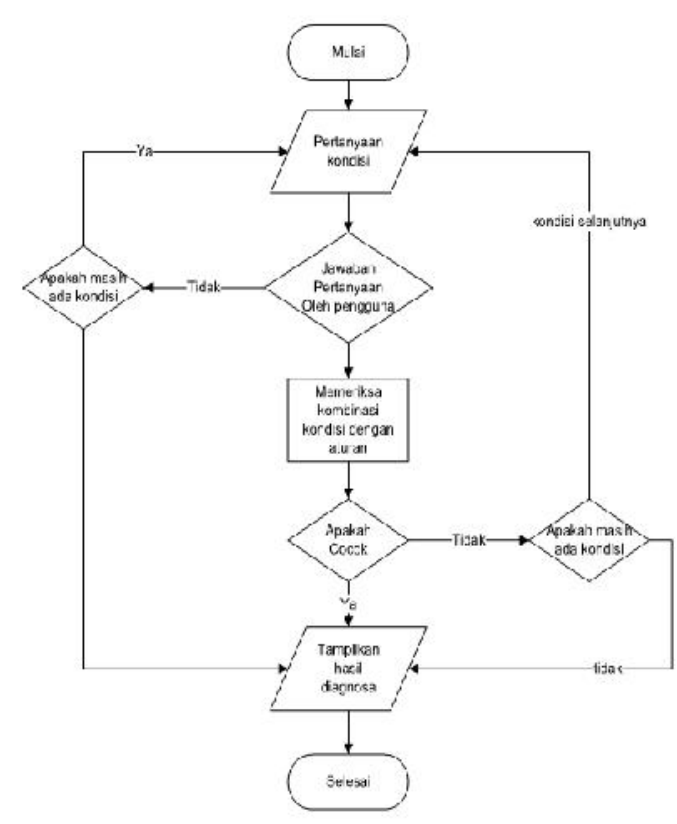

Gambar 3 Flowchart mesin inferensi

(Sumber: Data Penelitian, 2017)

Desain UML (Unified Modeling Language)

Diagram $U M L$ yang akan digunakan dalam penelitian ini antara lain:

1. Use case diagram

Aktor yang digunakan dalam sistem pakar ini terdiri dari 2 orang yaitu administrator dan pengguna. Dalam sistem pakar ini, yang berperan sebagai administrator adalah peneliti sendiri sedangkan penggunanya adalah tekisi yang masih baru atau pengguna awam yang ingin menangani permasalahan yang berkaitan dengan kerusakan SMAW.

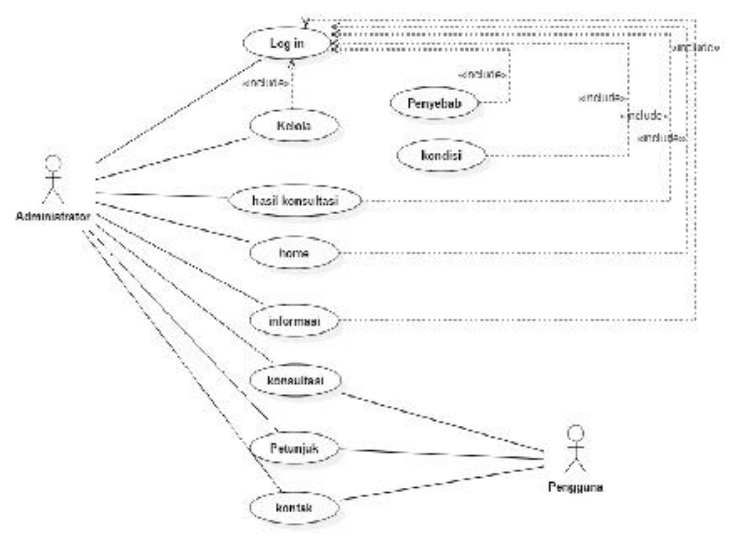

Gambar 4 Use case diagram

(Sumber: Data Penelitian, 2017)

\section{Activity Diagram}

Activity diagram yang dirancang untuk sistem pakar dalam penelitian ini akan ditunjukkan melalui gambar dibawah ini:

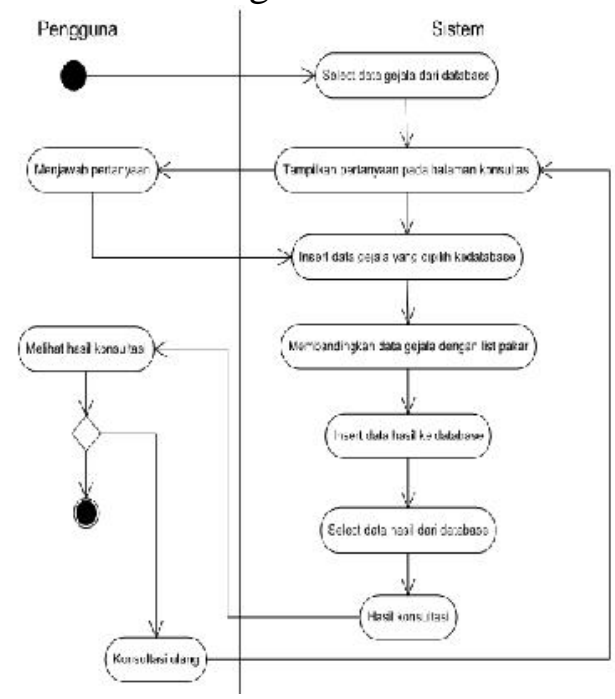

Gambar 5 Activity diagram pendaftaran konsultasi

(Sumber: Data Penelitian, 2017)

\section{Sequence diagram}

Berikut ini adalah gambar-gambar sequence diagram yang digunakan dalam sistem pakar pada penelitian ini: 


\section{Jurnal Edik Informatika \\ ISSN : 2407-0491 \\ E-ISSN : 2541-3716}

Penelitian Bidang Komputer Sains dan Pendidikan Informatika V3.i2(211-225)

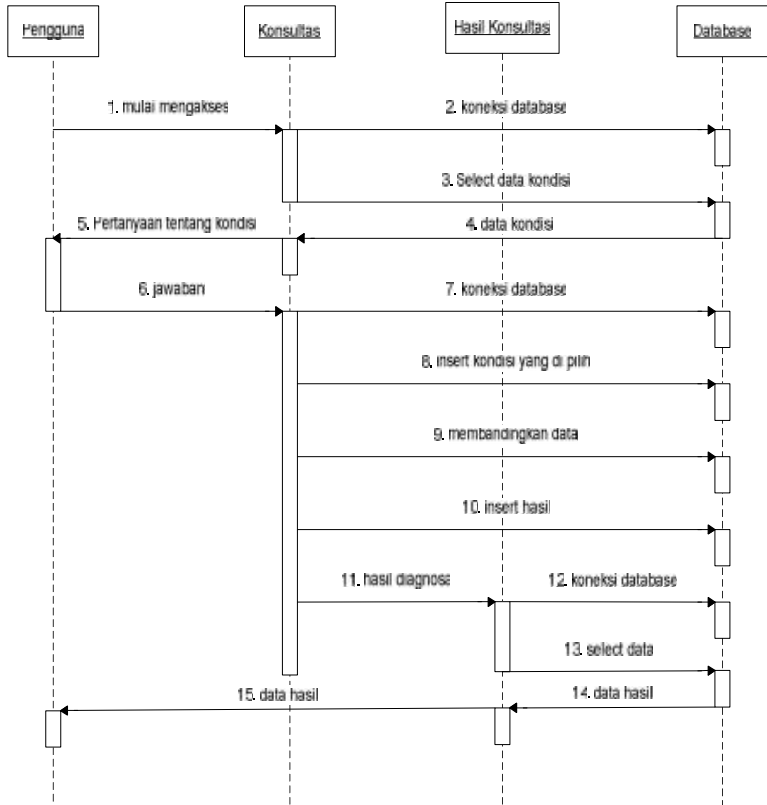

Gambar 6 Sequence diagram konsultasi

(Sumber: Data Penelitian, 2017)

\section{Desain Database}

Berikut ini adalah gambar database yang di gunakan dalam sistem pakar:

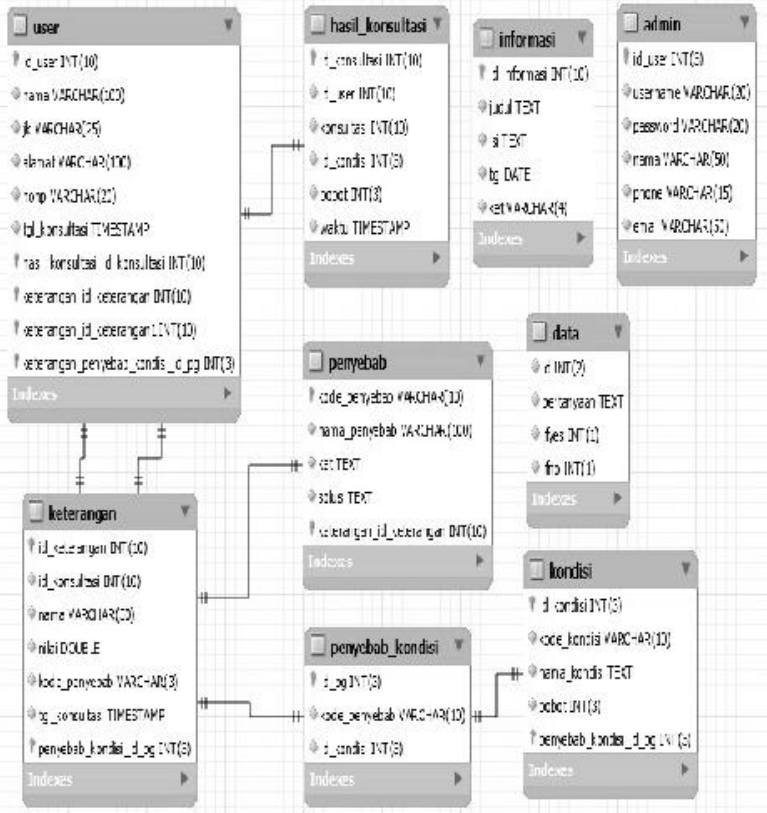

Gambar 7 Physical Data Model

(Sumber: Data Penelitian, 2017)

\section{Desain Antarmuka}

Berikut merupakan rancangan antar muka (interface) dalam aplikasi sistem pakar untuk mendeteksi kesalahan elektroda pada proses welding frame thermostat pada soulplate menggunakan metode forward chaining berbasis web:

1. Halaman Konsultasi

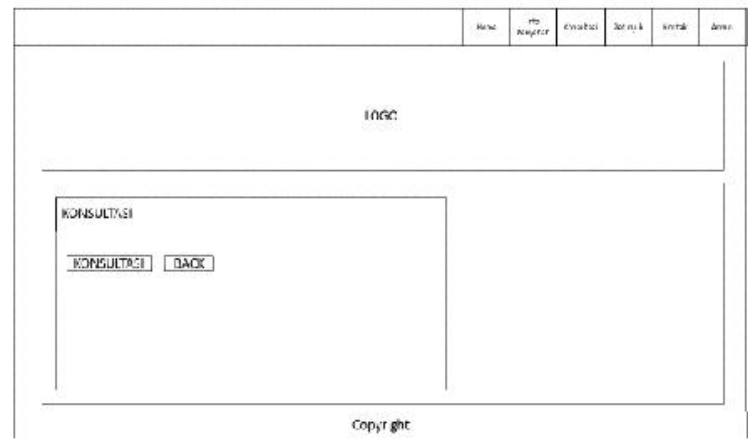

Gambar 8 Halaman Konsultasi

(Sumber: Data Penelitian, 2017)

2. Halaman pertanyaan

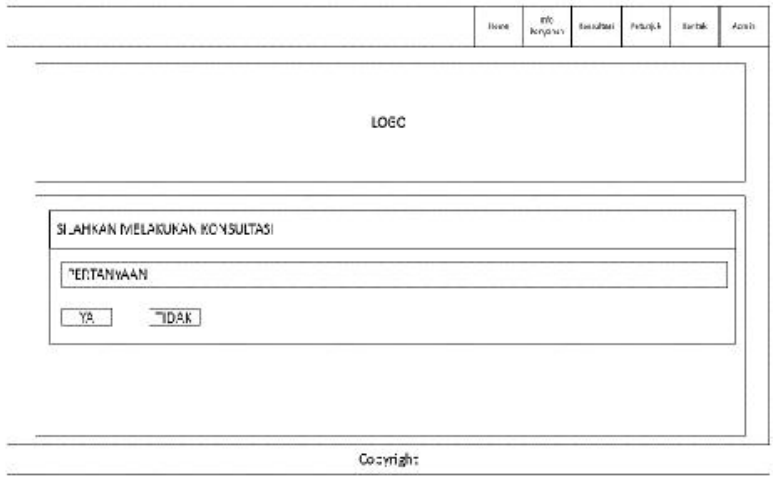

Gambar 9 Halaman pertanyaan

(Sumber: Data Penelitian, 2017)

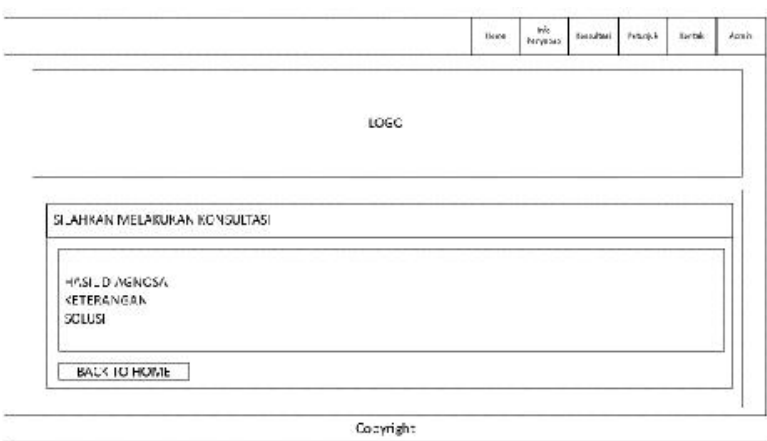

Gambar 10 Halaman Hasil

(Sumber: Data Penelitian, 2017) 


\section{Jurnal Edik Informatika \\ E-ISSN : 2541-3716}

ISSN : 2407-0491

Penelitian Bidang Komputer Sains dan Pendidikan Informatika V3.i2(211-225)

3. Halaman Login admin

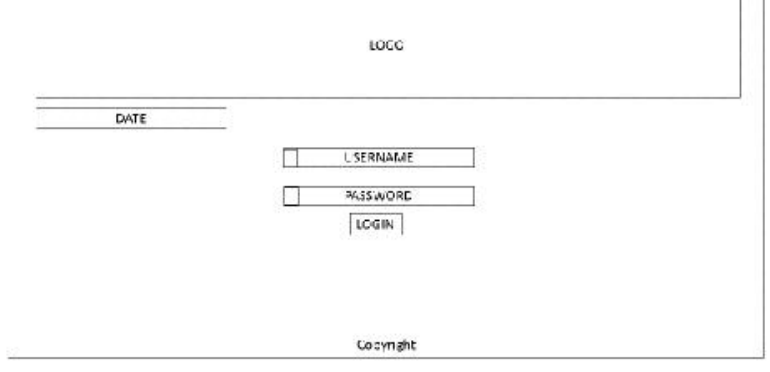

Gambar 11 Halaman Login Admin

(Sumber: Data Penelitian, 2017)

\section{Halaman Kelola kondisi}

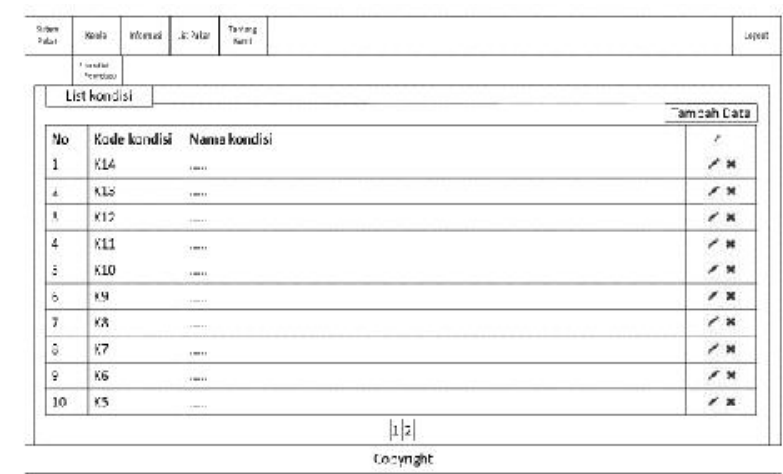

\section{Gambar 12 Halaman Kelola Kondisi}

(Sumber: Data Penelitian, 2017)

5. Halaman Kelola Penyebab

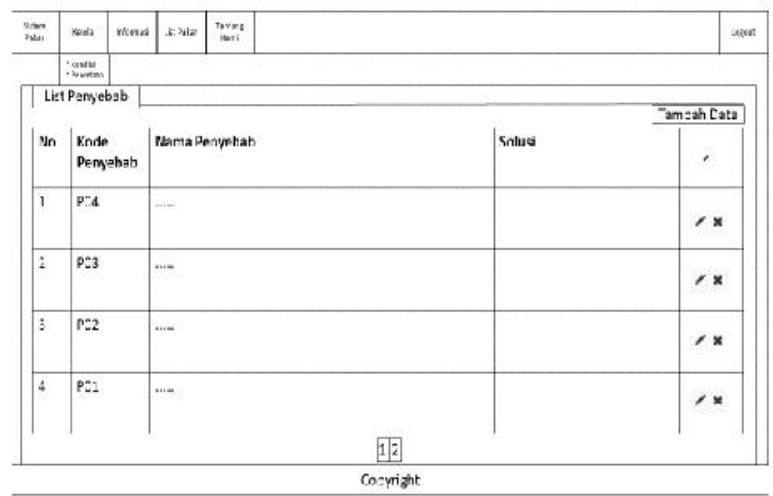

Gambar 13 Halaman Kelola Penyebab

(Sumber: Data Penelitian, 2017)
6. Halaman List Pakar

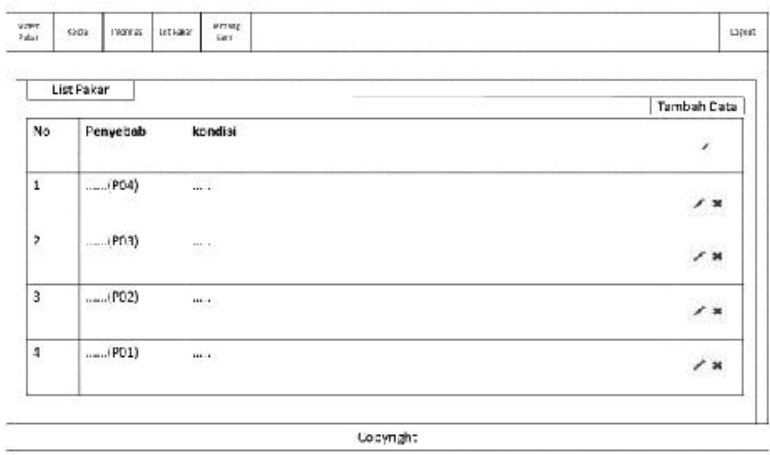

Gambar 14 Halaman List Pakar

(Sumber: Data Penelitian, 2017)

\section{HASIL DAN PEMBAHASAN \\ Hasil Penelitian}

Hasil penelitian ini berupa sistem pakar untuk mendeteksi kerusakan pengelasan pada SMAW menggunakan metode forward chaining berbasis web. Sistem pakar ini terdiri dari 2 bagian yaitu Menu Utama dan Menu Administrasi.

1. Menu Utama

Menu Utama adalah menu yang muncul saat pertama kali pengguna mulai mengakses sistem. Menu Utama dapat diakses oleh orang yang mau melakukan konsultasi.

a. Konsultasi

Menu Konsultasi digunakan oleh pengguna untuk melakukan konsultasi dalam mendeteksi kerusakan Pengelasan SMAW.

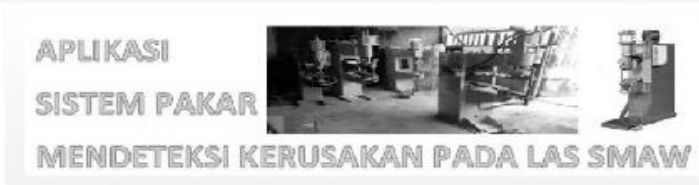

Kenรultaรเ

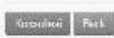

Gambar 15 Form Konsultasi

(Sumber: Data Penelitian, 2017) 


\section{Jurnal Edik Informatika \\ ISSN : 2407-0491 \\ E-ISSN : 2541-3716}

Penelitian Bidang Komputer Sains dan Pendidikan Informatika V3.i2(211-225)

Pada menu Diagnosa, pengguna akan diberikan pertanyaan-pertanyaan tentang kondisi kerusakan yang mungkin terjadi pada perangkat las SMAW pengguna. Pengguna hanya diminta untuk menjawab pertanyaan dengan pilihan jawaban "ya" atau "tidak" sesuai dengan fakta yang terjadi pada las SMAW.

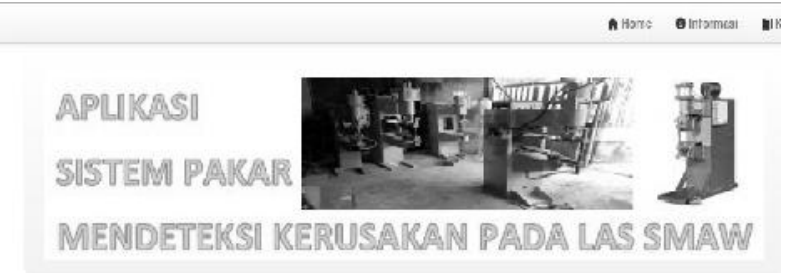

Silahkan Molakukan Konsultasi

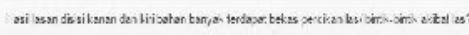

natim

Gambar 16 Klik ya atau tidak kondisi yang dialami

(Sumber: Data Penelitian, 2017)

Setelah memilih kondisi yang dialami, maka sistem akan melakukan proses pencarian hasil dan menampilkan hasil pada halaman konsultasi.

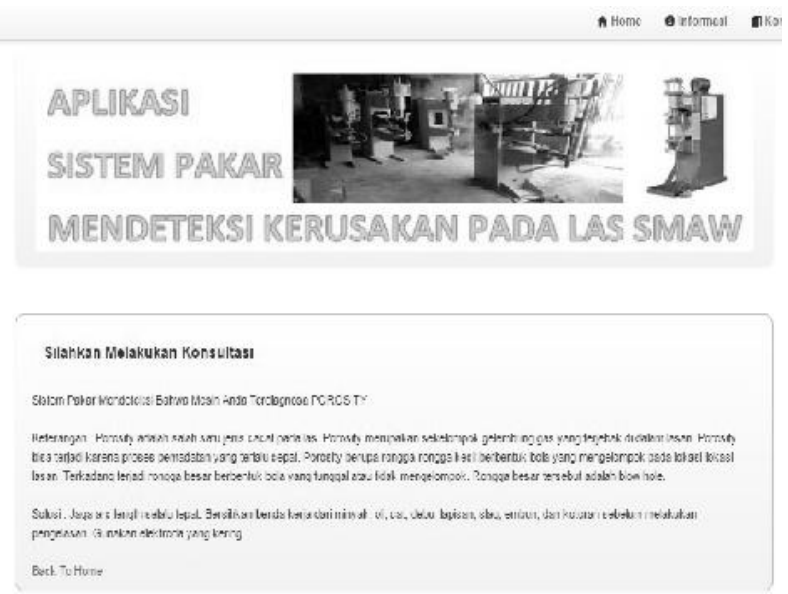

Gambar 17 Hasil Konsultasi

(Sumber: Data Penelitian, 2017)

b. $\log I n$

Menu Log In digunakan oleh administrator atau pakar sebelum dapat mengakses Menu Administrasi. Administrator atau pakar harus mengisi form Log In dengan username dan password yang sesuai. Prosedur ini dibuat untuk menghindari pengguna yang tidak berhak dapat mengakses Menu Administrasi.

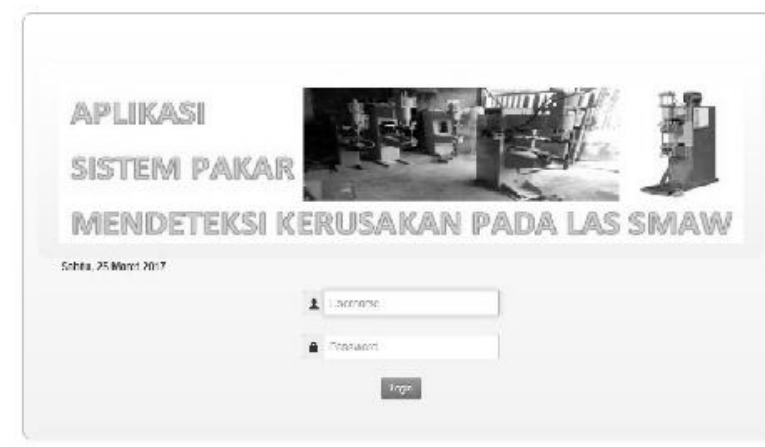

\section{Gambar 18 Form Log In}

(Sumber: Data Penelitian, 2017)

\section{Menu Administrasi}

Menu Administrasi merupakan menu yang digunakan oleh administrator atau pakar untuk mengelola data-data yang digunakan dalam sistem pakar. Data yang dapat dikelola antara lain: hasil konsultasi pasien dan Kelola (kondisi, dan Penyebab).

\section{Kelola - kondisi}

Menu ini berisi tabel yang menampilkan data-data penyebab kerusakan yang telah dimasukkan oleh administrator atau pakar.

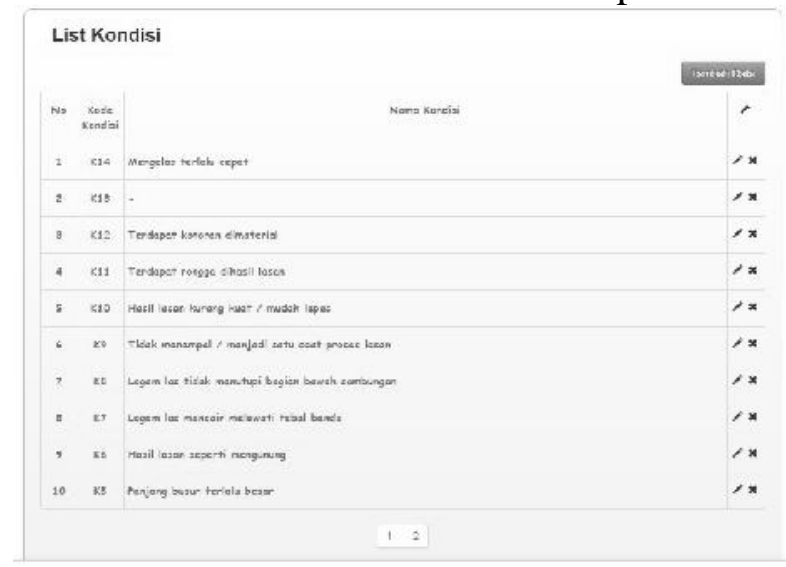

Gambar 19 Kelola - kondisi

(Sumber: Data Penelitian, 2017) 


\section{Jurnal Edik Informatika \\ ISSN : 2407-0491}

Penelitian Bidang Komputer Sains dan Pendidikan Informatika V3.i2(211-225)

Dalam menu tersebut, administrator atau pakar dapat menambahkan data kondisi dengan menekan tombol menu Tambah Data lalu mengisi Form Tambah Data.

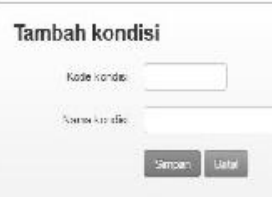

\section{Gambar 20 Form Tambah Data kondisi}

(Sumber: Data Penelitian, 2017)

Tombol ' (Edit) pada menu Kelola kondisi dapat digunakan oleh administrator atau pakar jika hendak mengubah isi dari data kondisi yang ada melalui Form Edit Data kondisi.

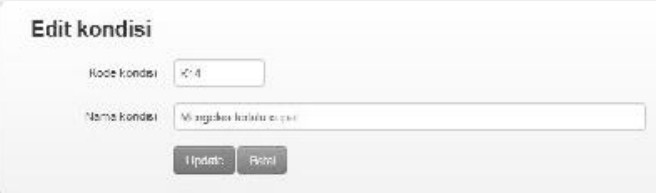

\section{Gambar 21 Form Edit Data kondisi \\ (Sumber: Data Penelitian, 2017)}

\section{Kelola - Penyebab}

Untuk melihat data penyebab secara detail, administrator atau pakar dapat menekan tombol Lihat pada menu Kelola - Penyebab. Sistem akan menampilkan informasi yang berkaitan dengan data Penyebab yang telah dipilih, seperti kode Penyebab, nama Penyebab, dan solusi.

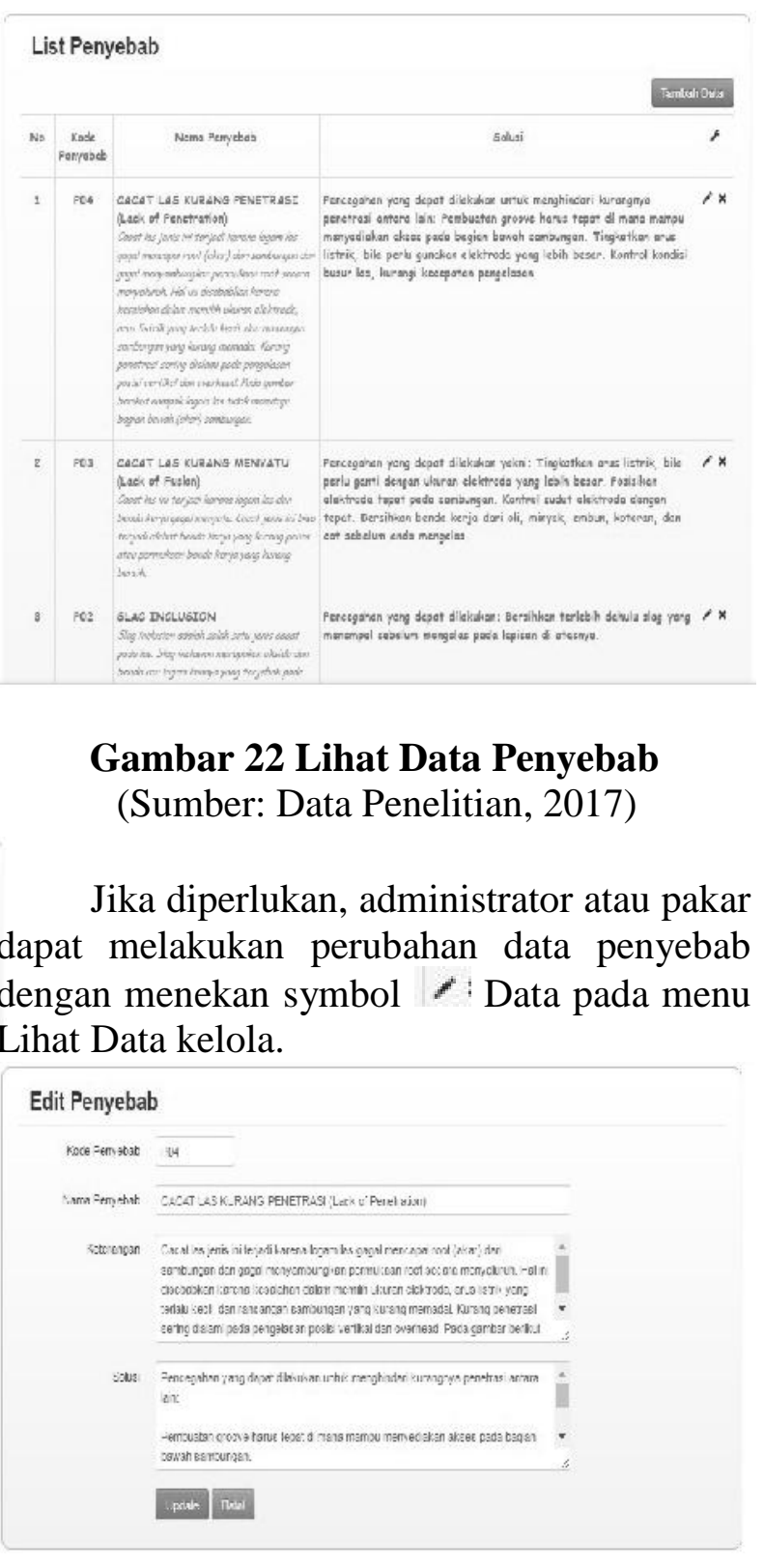

Gambar 23 Form Edit Data Penyebab

(Sumber: Data Penelitian, 2017)

3. kondisi Penyebab

Menu ini disediakan untuk membuat aturan (rule) yang akan digunakan dalam sistem pakar. Dalam menu ini, terdapat 3 data yang dapat direlasikan yaitu data bagian kerusakan, data penyebab, dan data kondisi. Setelah ketiga data direlasikan, data aturan tersebut dapat disimpan dengan menekan tombol Simpan. 


\section{Jurnal Edik Informatika \\ E-ISSN : 2541-3716}

ISSN : 2407-0491

Penelitian Bidang Komputer Sains dan Pendidikan Informatika V3.i2(211-225)

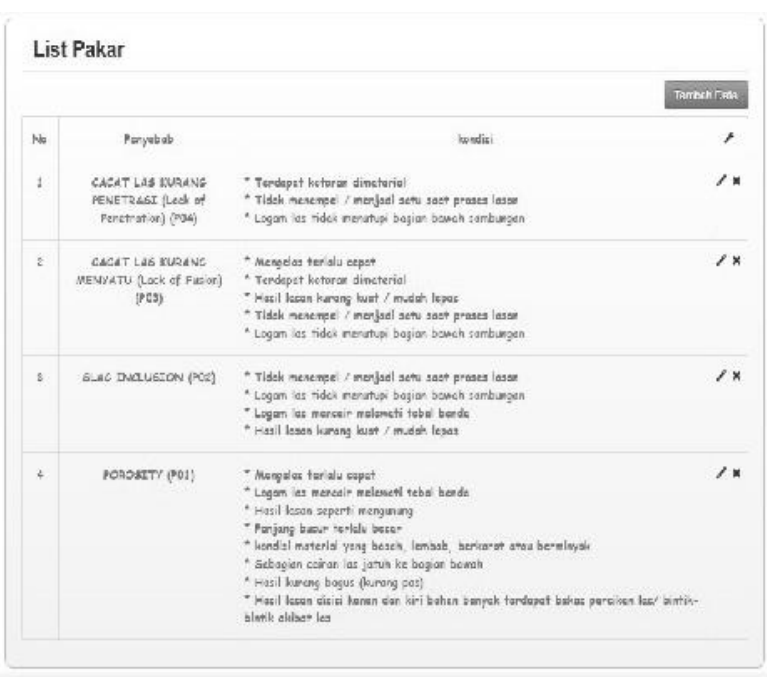

Gambar 24 Kondisi Penyebab

(Sumber: Data Penelitian, 2017)

\section{Pengujian Validasi System}

Proses pengujian ini dilakukan untuk mengetahui apakah masukan (input) yang dimasukkan dapat menghasilkan keluaran (output) yang diharapkan sesuai dengan kebutuhan.

Berikut ini hasil pengujian validasi dari sistem pakar pada penelitian ini:

Tabel 5 Pengujian Menu Konsultasi

\begin{tabular}{|c|c|c|c|}
\hline Masukan & Harapan & $\begin{array}{l}\text { Keluara } \\
\mathrm{n}\end{array}$ & $\begin{array}{l}\text { Kesimpu } \\
\text { lan }\end{array}$ \\
\hline $\begin{array}{l}\text { Klik } \\
\text { menu } \\
\text { Konsultas } \\
\mathrm{i}\end{array}$ & $\begin{array}{l}\text { Menampilkan } \\
\text { Form } \\
\text { Pendaftaran }\end{array}$ & $\begin{array}{l}\text { Menamp } \\
\text { ilkan } \\
\text { Form } \\
\text { Pendafta } \\
\text { ran }\end{array}$ & Sesuai \\
\hline $\begin{array}{l}\text { Nama, } \\
\text { jenis } \\
\text { kelamin, } \\
\text { Alamat, } \\
\text { klik } \\
\text { Konsulta } \\
\text { si }\end{array}$ & $\begin{array}{l}\text { Menampilkan } \\
\text { halaman } \\
\text { Konsultasi }\end{array}$ & $\begin{array}{l}\text { Menamp } \\
\text { ilkan } \\
\text { halaman } \\
\text { Konsulta } \\
\text { si }\end{array}$ & Sesuai \\
\hline $\begin{array}{l}\text { Memilih } \\
\text { pertanyaa } \\
\mathrm{n} \text { dengan } \\
\text { benar }\end{array}$ & $\begin{array}{l}\text { Menampilkan } \\
\text { hasil konsultasi }\end{array}$ & $\begin{array}{l}\text { Menamp } \\
\text { ilkan } \\
\text { hasil } \\
\text { konsulta } \\
\text { si }\end{array}$ & Sesuai \\
\hline
\end{tabular}

Sumber: Data Penelitian (2017)

\section{SIMPULAN}

Berdasarkan hasil dan pembahasan dalam penelitian ini. Adapun kesimpulan antara lain:

1. Model representasi pengetahuan berbasis kaidah produksi (production rule) dapat diterapkan dalam sistem pakar untuk mendeteksi kerusakan las $S M A W$ berbasis web.

2. Metode forward chaining dapat diterapkan dalam sistem pakar untuk mendeteksi kerusakan las $S M A W$ berbasis web.

3. Sistem pakar untuk mendeteksi kerusakan las SMAW menggunakan metode forward chaining berbasis web dapat digunakan untuk membantu teknisi dan operator di perusahaan dalam menangani permasalahan yang berkaitan dengan las SMAW.

\section{Saran}

Penelitian ini diharapkan agar bermanfaat bagi mahasiswa dan masyarakat agar dapat di gunakan dalam kehidupan sehari hari, serta bisa dilanjutkan dan dikembangkan ke dalam bentuk yang lebih luas agar menghasilalkan penelitian yang lebih berkualitas. diharapkan hasil penelitian ini bisa dijadikan acuan dasar dalam membentuk sistem di masa yang akan datang dan bahan referensi untuk penelitian ke depannya.

\section{DAFTAR PUSTAKA}

Hartati, S. dan S. Iswanti. (2008). Sistem Pakar dan Pengembangannya. Edisi Pertama. GRAHA ILMU. Yogyakarta.

Kusrini. (2008). Aplikasi Sistem Pakar Menentukan Faktor Kepastian Pengguna dengan Metode Kuantifikasi Pertanyaan. Edisi Pertama. PENERBIT ANDI. Yogyakarta. 
Sutojo, T.; E. Mulyanto, dan V. Suhartono. (2011). Kecerdasan Buatan. Edisi Pertama. PENERBIT Yogyakarta.

Sukaini, Tarkina, \& fandi. (2013). Teknik Las SMAW untuk SMK/MAK kelas $X$.
Jakarta: Kementerian Pendidikan \& Kebudayaan.

ANDI. Sarwono, J. (2006). Metode Penelitian Kuantitatif dan Kualitatif. Edisi Pertama. GRAHA ILMU. Yogyakarta. 